\title{
KEHADIRAN SOSIAL DALAM PEMBELAJARAN DARING BERDASARKAN SUDUT PANDANG PEMBELAJAR PENDIDIKAN TERBUKA DAN JARAK JAUH
}

\author{
Niki Raga Tantri \\ Tutor Tutorial Online, Universitas Terbuka \\ e-mail: nikitantri@gmail.com
}

\begin{abstract}
This research describes whether the social presence can be obtained from online learning of distance education setting. Data in this study employed questionnaire adapted from Rovai (2002) which identified 3 aspects of social presence, namely connectedness aspect, learning aspect, and socio-emotional aspect. Data was taken from 60 students who participated in an 8-weeks online learning. The results showed that all aspects have positive attitudes from students' point of views. The students experienced connectedness aspect, learning aspect, and socio-emotional aspect in online learning regardless the learning situation which was mostly text-based setting.
\end{abstract}

Keywords: COI Framework, community of inquiry, online learning, social presence

Dalam kelas-kelas konvensional, kehadiran sosial baik antara pembelajar dengan tutor atau pembelajar dengan pembelajar terbukti telah membawa hasil yang signifikan terhadap hasil belajar yang didapat oleh pemelajar. Menurut Scholis-Mantha (2008) kehadiran sosial mampu meningkatkan proses pengajaran dan menambah pengalaman pembelajaran di dalam kelas. Selain itu, kehadiran sosial mampu melatih pembelajar untuk menerapkan dan mengembangkan kemampuan berkelompok (collaboration) sebagai implementasi dalam pembelajaran skill abad ke-21 (21st Century Skills) (Tantri, 2018). Dibalik kesuksesan hadirnya hubungan sosial dalam meningkatkan hasil belajar pemelajar, berbagai penelitian dan literatur mulai mengadaptasi metode atau kerangka pembelajaran untuk diterapkan dalam situasi pembelajaran daring.

Salah satu model pembelajaran daring yang sering digunakan adalah kerangka Community of Inquiry (Col) yang digagas oleh Garrison, Anderson, dan Archer (2010). Kerangka Col menempatkan 3 (tiga) elemen dalam pembelajaran daring, yaitu elemen kognitif, elemen pengajaran, dan elemen kehadiran sosial. Kerangka Col terinspirasi dari kegiatan belajar mengajar di kelas konvensional dimana menitikberatkan pada pentingnya kehadiran tutor dan pembelajar sebagai kunci partisipan dalam kesuksesan kegiatan pembelajaran (Garrison, Anderson \& Archer, 2000). Garrison melihat bahwa pembelajaran yang sukses dalam suatu kelompok dikarenakan adanya interaksi tiga elemen yang menjadi dasar dalam kerangka seperti pada Gambar 1. 


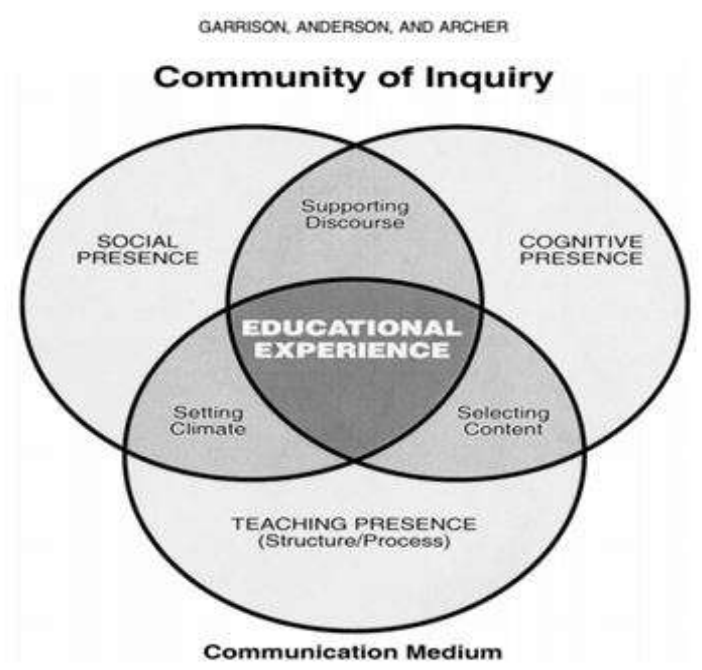

Gambar 1. Kerangka community of inquiry (Garnisson, Anderson, \& Archer, 2000)

Elemen kehadiran sosial hadir dalam kerangka COI dikarenakan kesuksesan pembelajaran dengan menggunakan komunikasi yang dimediasi oleh komputer (Computer Mediated Learning) diharapkan mampu membawa iklim kehadiran sosial seperti dalam kelas-kelas konvensional (Kosasih \& Iqbal, 2013). Di dalam kelas konvensional, kegiatan berkomunikasi dalam berkelompok dapat dilakukan dengan mengidentifikasi isyarat verbal yang didukung oleh isyarat non-verbal yang membawa informasi sosio-emosional sehingga pembicara satu dengan yang lain merasakan kehadiran fisik secara nyata (Short, Wiliams \& Christie, 1976). Adapun bentuk isyarat non-verbal diekspresikan dengan penglihatan (ekspresi wajah, arah memandang, postur tubuh, gerak-gerik, dan kontak mata), suara (volum, perubahan suara, kelembutan suara), peraba (menyentuh, bersalaman), dan penciuman (bau).

Namun yang menjadi perbedaan dalam mengimplementasikan kehadiran sosial di pembelajaran daring adalah karena pembelajaran dilaksanakan dalam media komunikasi asinkron berbasis teks sehingga diklaim pembelajaran dengan komunikasi yang dimediasi komputer sangat kurang akan isyarat sosial, baik verbal maupun non-verbal (Scholis-Mantha, 2008; Akcaoglu \& Lee, 2016). Oleh sebab itu, definisi dari kehadiran sosial dalam pembelajaran daring menjadi berubah, yaitu kemampuan partisipan dalam suatu kelompok bertanya (community of inquiry) untuk memproyeksikan diri mereka secara sosial dan emosional sebagai individu yang 'nyata' (Garrison, Anderson, dan Archer, 2000:94). Hal ini dikembangkan dalam 3 fase, yaitu fase mendapatkan sebuah identitas sosial, fase mempunyai komunikasi yang bermakna, dan fase membangun suatu hubungan. Sehingga, agar partisiapan berkeinginan untuk berpendapat dalam suatu kelompok diskusi dalam pembelajaran daring harus dibangun lingkungan yang aman, saling percaya satu sama lain, dan nyaman yang mengidentifikasikan kehadiran sosial terwujud dengan baik dalam pembelajaran tersebut. (Kosasih \& Iqbal, 2013; Kreijns, Acker, Vermeulen, \& Buuren, 2014).

Penelitian mengenai kehadiran sosial telah banyak dilakukan dan bentuknya terus berkembang. Dasar dari mengidentifikasi kehadiran sosial secara operasional dalam pembelajaran daring terbagi menjadi tiga (3), yaitu kepaduan dalam berkelompok (group cohesion), keterbukaan dalam berkomunikasi, dan ekspresi afektif (Garrison, Anderson, dan Archer, 2000). Pada mulanya, 
penelitian kehadiran sosial dilakukan dengan konten analisa dimana penelitian dilakukan dengan mengodekan jumlah emotikon yang dipakai di dalam posting pembelajar dan diidentifikasi bentuk kehadiran sosialnya. Namum hal ini tidak bisa digunakan terus menerus, dikarenakan metode penelitian analisa konten tidak bisa mengidentifikasi bentuk kehadiran sosial yang melibatkan interaksi berpikir kritis (Garrison, Anderson, dan Archer, 2010). Pada akhirnya, metode penelitian untuk mengidentifikasi hubungan sosial menggunakan transkrip dimana pengkodeannya berdasarkan pada tujuan yang diteliti dan disadari bahwa metode tersebut sulit dilakukan karena melibatkan beberapa pengkode dan membutuhkan waktu yang banyak untuk menyamakan internal representasi dari pengkode-pengkode tersebut sebelum peneliti memulai mengidentifikasi transkripnya.

Oleh sebab itu, muncul penelitian-penelitian mengenai validitas dalam analisis konten kuantitatif, yang salah satunya diteliti oleh Rovai (2002). Rovai mengembangkan instrumen untuk mengukur kehadiran komunitas kelas (classroom community) dalam suatu kelas berjarak dengan menggunakan internet. Kehadiran komunitas kelas diteliti dikarenakan banyaknya jumlah rata-rata pembelajar yang ke luar (drop-out) selama pembelajaran daring berlangsung dibandingkan dengan kelas-kelas tatap muka. Rovai (2002), mengidentifikasi hal ini disebabkan adanya pemisahan fisik pembelajar seperti berkurangnya rasa kebersamaan dengan adanya rasa ketidaksambungan (disconnectedness), terisolasi, terdistraksi, dan kekurangan perhatian individu yang dapat mempengaruhi pembelajar dalam melakukan pembelajan daring jarak jauh. Instrumen ini dinilai valid dengan menunjukkan konsistensi internal yang tinggi dan menunjukkan bukti bahwa skala keterhubungan (connectedness) dan skala pembelajaran yang menjadi skala instrumen ini, mampu menggambarkan keadaan kehadiran komunitas kelas pembelajaran daring.

Universitas Terbuka (UT) merupakan perguruan tinggi yang pembelajarannya menggunakan sistem pendidikan jarak jauh. Selain kelas-kelas tatap muka, UT juga menerapkan model pembelajaran daring melalui situs website yang sudah disediakan. Pembelajaran daring dilakukan dengan menggunakan Moodle sebagai aplikasi Learning Management System yang menyediakan fitur-fitur kegiatan pembelajaran kooperatif dan kolaboratif untuk para tutor dimana fitur ini dipilih sendiri oleh tutor untuk melaksanakan pengajaran secara daring (Hussein, Aditiawarman, dan Mohamed, 2007). Adapun kegiatan kolaboratif yang paling diutamakan dalam pembelajaran ini adalah kegiatan diskusi yang dinilai dalam fitur forum diskusi. Sedangkan kegiatan individu yang dinilai adalah proyek yang berupa tugas, latihan, dan kuis.

Dari latar belakang yang sudah disebutkan di atas, penelitian ini bertujuan untuk mengidentifikasi sejauh mana kehadiran sosial dalam pembelajaran daring yang sudah dilakukan oleh penulis. Kehadiran sosial dilihat dari 3 aspek, yaitu aspek keterhubungan, aspek pembelajaran, dan aspek sosial (social-emotional).

\section{KAJIAN PUSTAKA}

Penelitian kehadiran sosial bermunculan semenjak Garnison, Anderson, dan Archer (2000) mengemukakan kerangka Col dihadapan publik akademik. Selanjutnya, literatur lebih pada meneruskan kerangka tersebut dengan memberikan revisi aspek-aspek kerangka yang masih menimbulkan perdebatan dan isu yang salah satunya adalah kerangka aspek kehadiran sosial. Hal ini dikarenakan aspek kehadiran sosial dalam pembelajaran daring tidak mempunyai wujud bentuk komunikasi dan hanya dapat diukur dengan tingkatan (degree) (Kreijns, Acker, Vermeulen, \& Buuren, 2014). Selain itu, banyak pakar memperdebatkan apakah kehadiran sosial ditentukan oleh perangkat teknologi yang berhubungan dengan media komunikasi atau ditentukan oleh kelompok 
sosial yang menggunakan media tersebut (Gunawardena dan Zittle, 1997). Hal ini dibantah oleh Kreijns, Acker, Vermeulen, dan Buuren (2014) bahwa kehadiran sosial adalah berbentuk dua hal, yakni karakteristik fisik medium yang dijadikan komunikasi dan kemungkinan faktor sosial yang mempengaruhi seperti konteks sosial dan proses sosial. Selain itu, Kreijns, Acker, Vermeulen, \& Buuren (2014) mengusulkan jika kehadiran sosial pada kerangka Col juga mempertimbangkan tidah hanya "kehadiran social", namun juga "lingkungan social", sehingga desain wujud dan penerapan kehadiran sosial dalam pembelajaran daring dapat digambarkan dengan jelas.

Selanjutnya, Denoyelles, Zydney, dan Chen (2014) membuat literatur mengenai wujud dan penerapan kehadiran sosial dalam kegiatan forum diskusi di pembelajaran daring. Dalam tulisannya, terdapat 2 hal yang dapat memunculkan kehadiran sosial, yaitu, yang pertama, dengan memberi model petunjuk-petunjuk kehadiran sosial. Hal ini dapat diwujudkan dengan tutor memberikan dorongan kepada pemelajar, menyebut nama pembelajar ketika sedang berdiskusi, tutor memberikan contoh perkenalan diri, dan yang paling penting adalah tutor memberikan contoh berkomentar dalam forum diskusi dalam bentuk ketika memberikan saran pada pemelajar, mengevaluasi komentar pemelajar, dan bentuk refleksi diri. Hal ini dapat memunculkan pembelajaran kolaboratif dan kepercayaan dalam pembelajaran berkelompok sesuai dengan karakteristik kehadiran sosial dalam kerangka Col (Denoyelles, Zydney, \& Chen, 2014). Yang kedua adalah mengadakan kegiatan diskusi wajib dan dinilai. Hal ini dapat memunculkan motivasi ekstrinsik pembelajar untuk berinteraksi dan berkontribusi dalam kegiatan diskusi yang produktif. Adapun kegiatan diskusi ini dengan menekankan pada keaktifan pembelajar dan tutor hanya sebagai fasilitator. Selain itu, bentuk forum diskusi yang mempunyai arahan atau aturan (protocol-based discussion) lebih membentuk kesadaran berkelompok daripada diskusi lepas (free-form discussion) (Zydney, Denoyelles, \& Seo, 2012).

Setelah itu, penelitian kehadiran sosial semakin berkembang. Para peneliti mulai dapat mengukur tingkatan kehadiran sosial dalam pembelajaran daring. Akcaoglu dan Lee (2016) meneliti tentang kehadiran sosial melalui grup diskusi kecil dengan melihat dari segi kemampuan sosial, lingkungan sosial, dan kerjasama grup pemelajar. Hasilnya adalah grup dengan anggota lebih sedikit mampu meningkatkan kehadiran sosial. Adapun Aydin \& Gumus (2016) menginvestigasi apakah ada rasa komunitas dalam kelas pada pemelajar, persepsi mengenai kesuksesan dalam proses pengembangan tim dan keinginan pembelajar belajar dalam tim. Hasilnya bahwa terdapat hubungan dalam rasa komunitas dalam kelas dan persepsi mengenai kesuksesan dalam proses pengembangan tim. Selain itu, Aydin \& Gumus (2016) juga menemukan jika rasa komunitas dalam kelas juga dapat dijadikan indikator sukses dalam kerja kelompok. Selanjutnya, Swan \& Shih (2005) menemukan korelasi antara kesadaran mengenai kehadiran sosial dan kepuasan dalam berdiskusi daring. Kesadaran kehadiran tutor lebih mempengaruhi kepuasan pembelajar daripada kesadaran kehadiran akan teman sebaya. Hasil penemuannya menunjukkan bahwa pembelajar yang mempunyai kesadaran kehadiran sosial yang tinggi serta mampu menemukan kegunaan dan tujuan dalam pembelajaran daring lebih sering berkontribusi dalam forum diskusi.

Dari literatur di atas menunjukkan bahwa kajian kehadiran sosial muncul dikarenakan terdapat pembeda antara kehadiran sosial dalam kelas tradisional dan kelas daring. Definisi dan wujudnya juga berkembang mengikuti persepsi berdasarkan perangkat teknologi yang digunakan serta lingkungan sosial yang menyertai pemelajar. Oleh sebab itu, penelitian mengenai kehadiran sosial dalam konteks pembelajaran daring di Indonesia, khususnya di Universitas Terbuka; sebagai universitas yang menyelenggarakan pembelajaran jarak jauh, perlu digali agar dapat mengidentifikasi 
pola kehadiran sosial pembelajar yang berhasil serta mewujudkan kesuksesan pembelajaran daring yang efektif.

\section{METODE PENELITIAN}

Jumlah responden dalam penelitian ini adalah 60 pembelajar yang telah terlibat dalam pembelajaran daring selama 8 minggu penuh dan tidak ada sesi pengajaran tatap muka dalam 8 minggu tersebut secara daring maupun luring. Responden terbagi dalam 4 kelas yang berbeda dengan mata kuliah dalam lingkup yang sama, yaitu pembelajaran Bahasa Inggris. Adapun jurusan yang menjadi subjek penelitian adalah kelas Bahasa Inggris 1, dimana kelas ini diikuti oleh pembelajar selain jurusan Sastra Inggris dan Reading 1 serta Writing 2 yang respondennya berasal dari pembelajar jurusan Sastra Inggris. Setelah pembelajaran selasai, di minggu ke-8 para pembelajar diminta kesediannya untuk mengisi kuesioner yang sudah dibagikan secara daring yang ditautkan dalam website pembelajaran.

Untuk mengidentifikasi sudut pandang pembelajar terhadap kehadiran sosial di dalam pembelajaran daring yang sudah mereka alami, penulis menggunkan kuesioner Rovai (2002) yang sudah diadaptasi dan diterjemahkan ke dalam Bahasa Indonesia, mengingat tidak semua responden berasal dari jurusan Sastra Inggris. Seperti yang sudah dijelaskan pada poin pendahuluan, kuisioner Rovai (2002) digunakan karena sudah terbukti valid untuk mengidentifikasi kehadiran sosial dalam konteks kelas komunitas dengan skala keterhubungan (connectedness) dan skala pembelajaran.

Kuesioner terdiri dari 4 bagian. Bagian pertama fokus pada informasi latar belakang responden, seperti jenis kelamin, nama kota di mana pembelajar saat ini sedang belajar, dan kelas daring (disebut sebagai Tutorial Online atau Tuton). Bagian kedua dalam kuesioner mengeksplorasi persepsi pembelajar terhadap aspek keterhubungan dalam Tuton yang sudah dialami. Bagian selanjutnya adalah menekankan pada aspek pembelajaran dalam Tuton yang berhubungan dalam konteks interaksi sosial dan bagian terakhir adalah mengidentifikasi bentuk aspek sosial (Kreijns, Acker, Vermeulen, \& Buuren, 2014) dalam pembelajaran Tuton.

Adapun model pembelajaran daring yang sudah diterapkan mempunyai pola yang sama antara satu kelas dengan yang lain. Pembelajaran berlangsung secara asinkronus. Dalam 8 inisiasi, tutor memberikan rangkuman materi pembelajaran dari buku wajib UT berbentuk powerpoint atau Pdf dan memberikan sumber pembelajaran lain seperti alamat website atau link pendukung materi atau video OER pendukung. Selain itu, pembelajar diwajibkan untuk berpartisipasi dalam kegiatan diskusi yang ada dalam tiap inisiasi dan mengumpulkan 3 buah tugas di minggu ke-3, 5, dan 7 . Yang menjadi tambahan dalam pembelajaran daring yang dilakukan adalah adanya forum diskusi "memperkenalkan diri" di inisiasi 1 dengan nama 'getting to know each other'. Selain itu, tutor memberikan aturan atau netiket (netiquette) pada diskusi forum agar pembelajar wajib memberi komentar pada postingan peserta tuton yang lain minimal 1 posting setelah pembelajar tersebut memposting jawaban pertanyaan diskusi pada kolom komentar yang sudah disediakan. Adapun komentar yang diberikan tidak boleh hanya menyatakan "ya/tidak" dan "setuju/tidak setuju" tetapi beserta alasan mengapa pembelajar setuju atau tidak setuju dengan pendapat peserta tuton yang lain.

\section{HASIL TEMUAN}

Tujuan dari penelitian ini adalah untuk mengidentifikasi sejauh mana kehadiran sosial dalam pembelajaran daring yang sudah dilakukan oleh penulis dilihat dari 3 aspek, yaitu aspek keterhubungan, aspek pembelajaran, dan aspek sosial (social-emotional). Dengan demikian, 
kuesioner dalam bentuk elektronik telah ditautkan pada tiap kelas tuton di akhir inisiasi. Para pembelajar diminta untuk mengisi latar belakang pembelajar seperti di mana pembelajar belajar saat ini (kota), jenis kelamin, dan kelas Tuton yang sudah diikuti. Tabel 1 menjelaskan latar belakang personal responden yang berpartisipasi dalam kuesioner.

Tabel 1. Deskripsi Responden

\begin{tabular}{|c|c|c|c|c|c|}
\hline & \multicolumn{5}{|c|}{ Jumlah responden } \\
\hline \multirow[t]{2}{*}{ Kelas } & $\begin{array}{c}\text { Bahasa Inggris } \\
1 \mathrm{~A} \\
(\%) \\
\end{array}$ & $\begin{array}{c}\text { Bahasa Inggris } \\
1 \mathrm{~B} \\
(\%) \\
\end{array}$ & $\begin{array}{c}\text { Reading } 1 \\
(\%)\end{array}$ & $\begin{array}{c}\text { Writing } 2 \\
(\%)\end{array}$ & $\begin{array}{l}\text { Total } \\
(\%) \\
\end{array}$ \\
\hline & $\begin{array}{c}8 \\
(13) \\
\end{array}$ & $\begin{array}{c}8 \\
(13)\end{array}$ & $\begin{array}{c}28 \\
(47)\end{array}$ & $\begin{array}{c}16 \\
(27)\end{array}$ & $\begin{array}{c}60 \\
(100) \\
\end{array}$ \\
\hline Jenis kelamin & \multicolumn{2}{|c|}{$\begin{array}{l}\text { Laki-laki } \\
(\%)\end{array}$} & \multicolumn{2}{|c|}{$\begin{array}{c}\text { Perempuan } \\
(\%)\end{array}$} & $\begin{array}{c}\text { Total } \\
(\%)\end{array}$ \\
\hline & \multicolumn{2}{|c|}{$\begin{array}{c}14 \\
(23)\end{array}$} & \multicolumn{2}{|c|}{$\begin{array}{c}46 \\
(77)\end{array}$} & $\begin{array}{c}60 \\
(100) \\
\end{array}$ \\
\hline
\end{tabular}

Dari Tabel 1 dapat diketahui bahwa responden terbanyak adalah pembelajar dari kelas Tuton Reading 1, yakni sebanyak 28 pembelajar (47\%) terlibat dalam pengisian kuisioner.

Selanjutnya diikuti pembelajar dari kelas Writing 2, yaitu sebanyak 16 pembelajar (27\%). Yang paling sedikit respondennya adalah dari kelas Bahasa Inggris 1 A dan Bahasa Inggris 1 B. Masing-masing hanya 8 responden (13\%) saja yang mengisi kuesioner. Adapun jenis kelamin responden yang dominan terlibat dalam penelitian ini adalah perempuan. Sebanyak 46 responden perempuan $(77 \%)$ terlibat dalam penelitian ini dan responden laki-laki yaitu 14 responden $(23 \%)$.

Tabel 2. Deskripsi Asal Kota (UPBJJ) Responden

\begin{tabular}{|c|c|c|c|}
\hline Kota (UPBJJ) & Jumlah responden & Kota (UPBJJ) & Jumlah responden \\
\hline Balikpapan & 2 & Majene & 1 \\
\hline Bandung & 7 & Makasar & 1 \\
\hline Batam & 4 & Malang & 2 \\
\hline Bengkulu & 1 & Manado & 1 \\
\hline Bogor & 5 & Medan & 1 \\
\hline Cianjur & 1 & Palangkaraya & 1 \\
\hline Denpasar & 4 & Pangkal pinang & 2 \\
\hline Jakarta & 17 & Purwokerto & 1 \\
\hline Jember & 1 & Samarinda & 1 \\
\hline Kendari & 1 & Surabaya & 4 \\
\hline Kuala lumpur & 1 & Surakarta & 1 \\
\hline Total & 44 & & $\Sigma=60$ \\
\hline
\end{tabular}

Tabel 3 menunjukkan hasil kuesioner mengenai sudut pandang pembelajar mengenai aspek keterhubugan dalam pembelajaran Tuton yang sudah dialami. Terdapat tiga belas (13) pertanyaan untuk menggali aspek ini. Dari data tersebut diketahui pembelajar mempunyai padangan yang positif 
terhadap sikap peserta lain dalam Tuton, termasuk sikap saling peduli dengan jumlah responden setuju yaitu 42 responden (70\%) dan sangat setuju 13 responden (22\%). Selain itu, responden merasa bahwa sudut pandangnya mudah dipahami oleh peserta Tuton yang lain dengan jumlah responden yang setuju adalah 40 responden (67\%) dan sangat setuju 12 responden (20\%).

Selanjutnya, terdapat 36 responden $(60 \%)$ setuju jika mereka merasa kekeluargaan dalam Tuton ini dan diikuti 12 responden (20\%) sangat setuju terhadap hal ini. Lalu, responden juga setuju (78\%) dan sangat setuju (18\%) jika mereka mempercayai satu sama lain.

Tabel 3. Sudut Pandang Pembelajar Mengenai Aspek Keterhubungan

\begin{tabular}{|c|c|c|c|c|c|c|c|c|c|}
\hline & \multirow[t]{2}{*}{ Item } & \multicolumn{2}{|c|}{ Sangat Setuju } & \multicolumn{2}{|c|}{ Setuju } & \multicolumn{2}{|c|}{ Tidak Setuju } & \multicolumn{2}{|c|}{$\begin{array}{l}\text { Sangat Tidak } \\
\text { Setuju }\end{array}$} \\
\hline & & $f$ & $\%$ & $f$ & $\%$ & $f$ & $\%$ & $f$ & $\%$ \\
\hline 1. & $\begin{array}{l}\text { Saya merasa bahwa peserta dalam } \\
\text { Tuton saling peduli satu sama lain. }\end{array}$ & 13 & 22 & 42 & 70 & 5 & 8 & 0 & 0 \\
\hline 2. & $\begin{array}{l}\text { Saya merasa bahwa sudut pandang saya } \\
\text { dipahami oleh peserta Tuton yang lain. }\end{array}$ & 12 & 20 & 40 & 67 & 8 & 13 & 0 & 0 \\
\hline 3. & $\begin{array}{l}\text { Saya merasakan kekeluargaan dalam } \\
\text { Tuton ini. }\end{array}$ & 12 & 20 & 36 & 60 & 12 & 20 & 0 & 0 \\
\hline 4. & $\begin{array}{l}\text { Saya mempercayai satu sama lain dalam } \\
\text { Tuton ini. }\end{array}$ & 11 & 18 & 47 & 78 & 2 & 3 & 0 & 0 \\
\hline 5. & $\begin{array}{l}\text { Saya merasa bahwa saya bisa } \\
\text { bergantung dengan yang lain. }\end{array}$ & 7 & 12 & 15 & 25 & 35 & 58 & 3 & 5 \\
\hline 6. & $\begin{array}{l}\text { Saya merasa bahwa anggota Tuton yang } \\
\text { lain bergantung pada saya. }\end{array}$ & 1 & 2 & 7 & 12 & 40 & 67 & 12 & 20 \\
\hline 7. & $\begin{array}{l}\text { Saya merasa percaya diri bahwa peserta } \\
\text { Tuton yang lain akan mendukung saya. }\end{array}$ & 7 & 12 & 44 & 73 & 9 & 15 & 0 & 0 \\
\hline 8. & $\begin{array}{l}\text { Perkenalan diri dengan peserta Tuton } \\
\text { yang lain memberikan saya rasa memiliki } \\
\text { dalam Tuton. }\end{array}$ & 17 & 28 & 40 & 67 & 3 & 5 & 0 & 0 \\
\hline 9. & $\begin{array}{l}\text { Komunikasi dalam bentuk online adalah } \\
\text { medium yang sangat bagus untuk } \\
\text { interaksi sosial. }\end{array}$ & 17 & 28 & 39 & 65 & 4 & 7 & 0 & 0 \\
\hline 10. & $\begin{array}{l}\text { Forum diskusi membantu saya dalam } \\
\text { mengembangkan rasa berkerjasama. }\end{array}$ & 13 & 22 & 44 & 73 & 3 & 5 & 0 & 0 \\
\hline 11. & $\begin{array}{l}\text { Saya tidak merasakan semangat } \\
\text { kebersamaan. }\end{array}$ & 0 & 0 & 10 & 17 & 33 & 55 & 17 & 28 \\
\hline 12. & Saya merasa terasing dalam Tuton ini. & 0 & 0 & 7 & 12 & 33 & 55 & 20 & 33 \\
\hline 13. & $\begin{array}{l}\text { Saya tidak yakin dengan peserta yang } \\
\text { lain dalam Tuton ini. }\end{array}$ & 0 & 0 & 7 & 12 & 37 & 62 & 16 & 27 \\
\hline
\end{tabular}

Namun, sebanyak 35 responden (58\%) tidak setuju dan sangat tidak setuju 3 responden $(5 \%)$ jika mereka tidak bisa bergantung dengan yang lain. Adapun pernyataan sebaliknya, yaitu peserta Tuton yang lain bergantung pada mereka terdapat 40 responden $(67 \%)$ yang tidak setuju dan 12 responden (20\%) yang sangat tidak setuju. Diikuti dengan 33 responden (55\%) tidak setuju dan 17 responden (28\%) sangat tidak setuju dengan pernyataan bahwa mereka tidak merasakan semangat kebersamaan dan mereka merasa terasing dalam pembelajaran Tuton tersebut. Selain itu, 
terdapat 37 responden (62\%) tidak setuju dan 16 responden (27\%) sangat tidak setuju jika mereka tidak yakin dengan peserta lain dalam Tuton.

Adapun sikap positif disampaikan responden mengenai item percaya diri, sesi perkenalan diri, komunikasi dalam bentuk online, dan forum diskusi. Responden merasa percaya diri jika peserta Tuton yang lain mendukung mereka dengan 44 responden (73\%) menjawab setuju dan 7 responden $(12 \%)$ menjawab sangat setuju. Sebanyak 40 responden (67\%) setuju dan 17 responden (28\%) jika sesi perkenalan diri memberikan mereka rasa memiliki dalam pembelajaran Tuton. Selain itu, 39 responden (65\%) setuju dan 17 responden (28\%) sangat setuju jika komunikasi dalam bentuk online adalah medium sangat bagus untuk interaksi sosial dan 44 responden (73\%) setuju dan 13 responden $(22 \%)$ sangat setuju jika forum diskusi membantu mereka mengembangkan rasa berkerjasama.

Tabel 4 menjelaskan mengenai hasil sudut pandang pembelajar mengenai aspek pembelajaran dalam kehadiran sosial di pembelajaran daring. Untuk menggali sudut pandang dalam aspek ini, terdapat total 13 item yang diberikan pada responden. Sebanyak 41 responden $(68 \%)$ setuju dan 14 responden (23\%) sangat setuju jika dalam pembelajaran daring mereka didorong untuk bertanya. Selanjutnya, 45 pembelajar setuju (75\%) dan 11 pembelajar sangat setuju (18\%) jika mereka merasa nyaman ketika bercakap-cakap dalam media online. Tidak hanya itu saja, sebanyak 42 responden setuju (70\%) dan 18 responden sangat setuju (11\%) sangat setuju ketika berpartisipasi dalam diskusi. Sebanyak 49 responden (82\%) setuju dan 11 responden sangat setuju (18\%) nyaman ketika berinteraksi dengan peserta tuton yang lain. Respon positif juga terlihat dalam peran pembelajaran daring membantu mengembangkan rasa kerjasama pembelajar dengan sebanyak 40 responden setuju (67\%) dan 14 responden sangat setuju (23\%) dengan item ini. Selain itu, 34 responden setuju (57\%) dan 8 responden sangat setuju (13\%) jika mereka menerima umpan balik tepat waktu. Waktu yang cukup untuk belajar juga dirasakan oleh 39 responden yang mengatakan setuju (65\%) dan 12 responden mengatakan sangat setuju (20\%). Bahkan, responden merasa nyaman ketika tidak setuju dengan peserta Tuton yang lain sebanyak 38 responden (63\%) yang setuju dan 3 responden (5\%) yang sangat setuju.

Responden merasa tidak setuju dan sangat tidak setuju mengenai item bahwa mereka merasa enggan untuk berbicara secara terbuka. Sebanyak 33 responden tidak setuju (55\%) dan 12 responden sangat tidak setuju (20\%) terhadap item ini. Begitu pula dengan 39 responden tidak setuju (65\%) jika peserta Tuton yang lain tidak membantu mereka belajar. Sebanyak 38 responden tidak setuju (63\%) dan 16 responden sangat tidak setuju (27\%) jika kebutuhan pendidikan/keilmuan tidak terpenuhi selama mengikuti pembelajaran daring serta 39 responden tidak setuju (65\%) dan 16 responden sangat tidak setuju (27\%) bahwa pembelajaran ini tidak mendorong keinginan untuk belajar. Selanjutnya, sebanyak 34 responden tidak setuju (57\%) dan 11 responden sangat tidak setuju (18\%) jika tidak mendapatkan bantuan ketika mereka memiliki pertanyaan.

Sedangkan aspek yang terakhir, yaitu aspek sosial mempunyai satu item, yaitu apakah pembelajar mampu menangkap kesan yang berbeda dari peserta Tuton yang lain. Item ini mendapat sudut pandang yang positif dari para responden. Sebanyak 43 pembelajar setuju (72\%) dan 9 pembelajar sangat setuju (15\%) jika mereka mampu menangkap kesan yang berbeda dari peserta Tuton yang lain. Adapun yang tidak setuju yaitu 7 pembelajar (12\%) dan yang sangat tidak setuju sebanyak 1 pembelajar (2\%). 
Tabel 4. Sudut Pandang Pembelajar Mengenai Aspek Pembelajaran

\begin{tabular}{|c|c|c|c|c|c|c|c|c|c|}
\hline \multicolumn{2}{|r|}{ Item } & \multicolumn{2}{|c|}{ Sangat setuju } & \multicolumn{2}{|c|}{ Setuju } & \multicolumn{2}{|c|}{ Tidak setuju } & \multicolumn{2}{|c|}{$\begin{array}{l}\text { Sangat tidak } \\
\text { setuju }\end{array}$} \\
\hline & & $f$ & $\%$ & $f$ & $\%$ & $f$ & $\%$ & $f$ & $\%$ \\
\hline 1 & $\begin{array}{l}\text { Saya merasa bahwa saya didorong untuk } \\
\text { bertanya }\end{array}$ & 14 & 23 & 41 & 68 & 5 & 8 & 0 & 0 \\
\hline 2 & $\begin{array}{l}\text { Saya merasa nyaman ketika bercakap-cakap } \\
\text { dalam media online }\end{array}$ & 11 & 18 & 45 & 75 & 4 & 7 & 0 & 0 \\
\hline 3 & $\begin{array}{l}\text { Saya merasa nyaman berpartisipasi dalam } \\
\text { diskusi }\end{array}$ & 18 & 30 & 42 & 70 & 0 & 0 & 0 & 0 \\
\hline 4 & $\begin{array}{l}\text { Saya merasa nyaman ketika berinteraksi } \\
\text { dengan peserta Tuton yang lain }\end{array}$ & 11 & 18 & 49 & 82 & 0 & 0 & 0 & 0 \\
\hline 5 & $\begin{array}{l}\text { Pembelajaran daring membantu saya } \\
\text { mengembangkan rasa kerjasama saya }\end{array}$ & 14 & 23 & 40 & 67 & 6 & 10 & 0 & 0 \\
\hline 6 & $\begin{array}{l}\text { Saya merasa bahwa saya menerima umpan } \\
\text { balik tepat waktu }\end{array}$ & 8 & 13 & 34 & 57 & 16 & 27 & 2 & 3 \\
\hline 7 & $\begin{array}{l}\text { Saya merasa bahwa saya diberikan waktu } \\
\text { yang cukup untuk belajar }\end{array}$ & 12 & 20 & 39 & 65 & 9 & 15 & 0 & 0 \\
\hline 8 & $\begin{array}{l}\text { Saya merasa nyaman untuk tidak setuju } \\
\text { dengan peserta Tuton lain dengan tetap } \\
\text { mempertahankan rasa percaya }\end{array}$ & 3 & 5 & 38 & 63 & 17 & 28 & 2 & 3 \\
\hline 9 & $\begin{array}{l}\text { Saya merasa enggan untuk berbicara secara } \\
\text { terbuka }\end{array}$ & 1 & 2 & 14 & 23 & 33 & 55 & 12 & 20 \\
\hline 10 & $\begin{array}{l}\text { Saya merasa peserta Tuton yang lain tidak } \\
\text { membantu saya belajar }\end{array}$ & 10 & 17 & 11 & 18 & 39 & 65 & 0 & 0 \\
\hline 11 & $\begin{array}{l}\text { Saya merasa bahwa kebutuhan } \\
\text { pendidikan/keilmuan saya tidak terpenuhi }\end{array}$ & 0 & 0 & 6 & 10 & 38 & 63 & 0 & 0 \\
\hline 12 & $\begin{array}{l}\text { Saya merasa bahwa pembelajaran ini tidak } \\
\text { mendorong keinginan untuk belajar }\end{array}$ & 1 & 2 & 4 & 7 & 39 & 65 & 16 & 27 \\
\hline 13 & $\begin{array}{l}\text { Saya merasa kesulitan untuk mendapatkan } \\
\text { bantuan ketika saya memiliki pertanyaan }\end{array}$ & 1 & 2 & 14 & 23 & 34 & 57 & 11 & 18 \\
\hline
\end{tabular}

\section{PEMBAHASAN}

Kehadiran sosial, selain elemen pengajaran dan elemen kognitif, dalam pembelajaran daring menjadi bagian yang penting untuk meraih keberhasilan pembelajaran daring yang bermakna seperti pembelajaran pada kelas tatap muka. Berdasarkan hasil dari kuesioner yang diisi oleh pembelajar pembelajaran daring di atas, dapat diketahui bahwa terdapat sudut pandang yang positif pada aspek keterhubungan. Sejalan dengan pendapat Rovai (2002) bahwa aspek keterhubungan sangat dibutuhkan dalam suatu komunitas pembelajaran daring. Hal ini dapat dilihat dengan adanya interaksi yang baik antara pembelajar dalam kelas daring, mempunyai ekspetasi yang sama, dan saling kepercayaan yang dibangun diantara para pembelajar (Gibbs, 1995). Rasa peduli, memahami sudut pandang antara satu pembelajar dengan pembelajar yang lain, rasa kekeluargaan, dan mempercayai satu sama lain mendapat sudut pandang yang positif terhadap pembelajaran daring yang sudah dilakukan. Selain itu pembelajaran ini juga mampu menumbuhkan rasa percaya diri jika peserta lain mempunyai persepsi yang sama dengan apa yang dimaksud oleh si pembelajar. Rasa kerjasama mampu ditumbuhkan dalam forum diskusi juga mempunyai sudut pandang yang positif 
dalam kelas daring ini, termasuk merasakan semangat kebersamaan, dan hampir semua pembelajar merasa tidak terasing dalam pembelajaran Tuton yang dilakukan. Hal ini mendukung pendapat Garrison, Anderson, dan Archer (2000) bahwa forum diskusi dalam pembelajaran daring mampu menyediakan proses kolaboratif dimana sikap kritis dalam percakapan dalam diskusi mampu didorong dan dipraktekkan. Proses kolaborasi yang menjadi pendekatan pembelajaran kritis pada masa kini harus mampu mengajak pembelajar untuk berbagi pengalaman sebagai tujuan dari mengonstruksi dan menyepakati arti pembelajaran yang berarti (meaningful learning) antara satu pembelajar dengan pembelajar yang lain.

Selain itu, kehadiran sosial dilihat dari aspek keterhubungan dalam hasil kuisioner pembelajaran daring dapat dikatakan muncul seperti kelas-kelas tatap muka. Walaupun di kelaskelas tatap muka lebih kaya dengan simbol-simbol berkomunikasi seperti simbol non-verbal dan simbol vokal daripada dalam pembelajaran daring yang lebih mengutamakan kegiatan diskusi berbasis teks, aspek keterhubungan masih muncul dimana para pembelajar juga menunjukkan sudut pandang yang positif terhadap rasa komunitas atau kolaboratif dalam pembelajaran Tuton. Aspek keterhubungan sangat diperlukan dalam kehadiran sosial untuk menumbuhkan rasa komunitas sehingga menghindari besarnya jumlah drop-out pembelajar dalam pembelajaran daring (Aydin \& Gumus, 2016).

Dalam aspek kehadiran sosial yang kedua, yaitu aspek pembelajaran, pembelajar mempunyai sikap yang positif untuk berinteraksi di dalam kelas Tuton, seperti rasa nyaman untuk berinteraksi sesama pembelajar, rasa nyaman berpartisipasi dalam diskusi, bercakap-cakap dalam media online, bahkan mereka didorong untuk bertanya. Kesuksesan dalam pembelajaran daring sangat bergantung pada partisipasi pembelajar pada aktifitas belajar dan interaksi yang terjadi di antara pembelajar (Aydin \& Gumus, 2016). Hal inilah yang dimaksud dalam aspek pembelajaran dari sudut pandang kehadiran sosial. Tingginya interaksi antar pembelajar dan bentuk dari keterhubungan sosial mampu meningkatkan kesuksesan belajar dan motivasi (Aydin \& Gumus, 2016). Selain itu, bentuk interaksi belajar dalam kehadiran sosial seperti waktu untuk belajar yang cukup, menerima umpan balik tepat waktu, perbedaan pendapat, keterbukaan dalam berpendapat, mendapat bantuan belajar dari pembelajar yang lain, kesesuain materi dengan kebutuhan keilmuan, dan dorongan keinginan belajar kesemuanya mempunyai respon yang positif dari pembelajar. Aspek pembelajaran yang baik akan memberikan pembelajar untuk mudah meraih tujuan pembelajaran dan mendapatkan pengalaman pembelajaran yang bermakna (Garnisson, Anderson, \& Archer, 2000; Rovai, 2002; Akcaoglu \& Lee, 2016).

Aspek terakhir dari kehadiran sosial adalah aspek sosial. Aspek ini muncul dikarenakan berhubungan dengan teori kehadiran sosial yang nampak dalam kehidupan nyata, bahwa kehadiran yang nampak karena adanya efek interpersonal antara dua pembicara dalam seting yang terorganisasi ketika menggunakan 4 tipe media komunikasi yang berbeda, yaitu media audio, video, telepon, dan pertemuan tatap muka dimana kesemua media mampu membawa tidak hanya komunikasi verbal tetapi juga non-verbal yang dikespresikan dengan visual dan simbol-simbol yang membawa informasi sosio-emosional (Short, Wiliams \& Christie, 1976). Semakin banyak media yang digunakan maka semakin baik tingkat komunikasinya, Hal ini diinterpretasikan dalam aspek sosial di dalam pembelajaran daring; apakah pembelajar mampu menangkap kesan yang berbeda dari peserta Tuton yang lain walaupun media komunikasi yang digunakan hanya berbasis teks. Hasil dari item ini mendapat respon yang positif dan mengindikasikan bahwa komunikasi yang baik tidak selalu dengan keberagaman media yang dihasilkan melainkan kemampuan pembelajar untuk memproyeksikan kondisi "nyata" selama berkomunikasi dalam pembelajarn daring (Garnisson, 
Anderson, \& Archer, 2010; Kreijns, Acker, Vermeulen, \& Buuren, 2014). Hal ini disimpulkan bahwa pembelajaran daring yang sudah dilakukan mampu menghadirkan hubungan sosial di antara pembelajar satu dengan pembelajar lain walaupun dengan media komunikasi dalam forum diskusi dan fitur berbasis teks yang lain.

\section{SIMPULAN}

Kehadiran sosial dalam pembelajaran daring sangat dikaitkan dengan salah satu elemen untuk meraih keberhasilan pembelajaran yang bermakna. Selain itu, kehadiran sosial dalam pembelajaran daring dinilai sangat penting untuk menghindari besarnya drop out pada pembelajar dikarenakan lingkungan belajar yang didominasi dengan model berbasis teks dan kurang tersedianya simbol-simbol komunikasi non-verbal dan informasi sosio-emosional seperti dalam kelas-kelas tatap muka. Dari penelitian yang sudah dilakukan, hubungan sosial mampu dihadirkan dalam pembelajaran kelas daring melalui sudut pandang pembelajar yang sudah mengalami pembelajaran tersebut. Kehadiran sosial dilihat dari 3 aspek yaitu aspek keterhubungan, aspek pembelajaran, dan aspek sosial. Adapun yang dapat dihadirkan dari aspek keterhubungan adalah adanya interaksi yang baik antara pembelajar, mempunyai ekspektasi yang sama terhadap hasil pembelajaran, rasa saling percaya, rasa peduli, rasa kekeluargaan, rasa kerjasama, dan tidak ada rasa keterasingan dalam kegiatan diskusi. Mengenai aspek pembelajaran dalam kehadiran sosial, pembelajar merasakan adanya rasa nyaman untuk berinteraksi sesama pembelajar, merasa didorong untuk bertanya, interaksi belajar yang baik, merasa mempunyai waktu belajar yang cukup, menerima umpan balik tepat waktu, perbedaan pendapat, keterbukaan dalam berpendapat, mendapat bantuan belajar dari pembelajar yang lain, kesesuain materi dengan kebutuhan keilmuan, dan dorongan keinginan belajar. Sedangkan aspek sosial yang muncul selama pembelajaran daring adalah pembelajar mampu menangkap kesan yang berbeda dari peserta pembelajaran daring yang lain walaupun hanya dengan media komunikasi forum diskusi dan fitur berbasis teks lainnya.

\section{REFERENSI}

Akcaoglu, M \& Lee, E. (2016). Increasing Social Presence in Online Learning Through Small Group Discussions. International Review of Research in Open and Distributed Learning. (17), (3).

Aydin, I. E \& Gumus, S. (2016). Sense of Clasroom Community and Team Development Process In Online Learning. Turkish Online Journal of Distance Education (TOJDE), (17), (1), (5), 60-77.

Denoyelles, A., Zydney, J.M., Chen, B. (2014). Strategies for Creating A Community of Inquiry Through Online Asynchronous Discussions. MERLOT Journal of Online Learning and Teaching. 10, 1, 153-165.

Garrison, D.R., Anderson, T., \& Archer, W. (2000). Critical Inquiry in a Text-Based Environment: Computer Conferencing in Higher Education. The Internet and Higher Education, 2(2-3): 87105.

Garrison, D.R., Anderson, T., \& Archer, W. (2010). The First Decade of The Community of Inquiry Framework: A Retrospective. Internet and Higher Education , 13, 5-9.

Gibbs, G. (1995). Assessing Student Centred Courses. Oxford: Oxford Centre for Staff Learning and Development.

Gunawardena, C.N. \& Zittle, F. (1997). Social Presence as A Predictor of Satisfaction Within A Computer Mediated Conferencing Environment. American Journal of Distance Education, 11, 3, 8-25. 
Hussein, R. Aditiawarman, U., \& Mohamed, N. (2007). E-learning Acceptance In A Developing Country: A Case of The Indonesian Open University. Dipresentasikan dalam konferensi German e-Science, Baden, Germany, May2-4, 2007.

Kosasih, L., lqbal, M. 2013. E-learning Dengan Menggunakan COI Framework. ComTEch (4), (2), 856-866.

Kreijns, K., Acker, F.V., Vermeulen, M., Buuren, H.V. (2014). Community of Inquiry: Social Presence Revisited. E-learning and Digital Media, (11), (1), 5-18.

Rovai, A.P. (2002). Development of An Instrument To Measure Classroom Community. The Internet and Higher Education, (5), 197-211.

Scollins-Mantha, B. (2008). Cultivating social presence in the online learning classroom: A literature review with recommendations for practice. International Journal of Instructional Technology and Distance Learning, 5(3), 1-15.

Short, J., Wiliams, E., \& Christie, B. (1976). The Social Psychology of Telecommunications. London: John Wiley \& Sons.

Swan, K \& Shih, L. F. (2005). On The Nature and Development of Social Presence in Online Course Discussions. Journal or Asynchronous Learning Networks, 9(3), 115-136.

Tantri, N.R. (2018). How Far Do We Utilize The E-Learning Platform To Achieve $21{ }^{\text {st }}$ Century Skills in Teaching and Learning Process in School Context? A Conceptual Review. Diperesentasikan dalam English Teacher's Best Practices, Universitas Negeri Surabaya.

Zydney, J.M. Denoyelles, A., \& Seo, K. (2012). Creating A Community of Inquiry in Online Environments: An Explorator Study on The Effect of Protocols on Interactions With Asynchronous Discussions. Computers \& Education, 58, 1, 77-87. 